\title{
Expediente
}

Kacili Zuchinali, Andréa Catrópa da Silva *

\section{Decolonialidade e Carnaval: Algumas Perspectivas e Contribuições para o Design no Brasil}

Kacili Zuchinali é formada em design gráfico pela Universidade do Sul de Santa Catarina, especialista em Formação de professores com ênfase para o Ensino Superior pelo IFSP e mestranda em design pela linha de pesquisa Teoria, História e Crítica do Design pela UAM.

<Kacilizuchinali@gmail.com>

Andréa Catrópa da Silva é professora no PPG-Design da Universidade Anhembi Morumbi, estuda as interfaces entre o design, a literatura e a tecnologia.<andrea.Catropa@anhembi.br> ORCID: 0000-0003-0185-8167
Resumo $\mathrm{O}$ artigo faz um breve apontamento histórico do pensamento decolonial e de seu legado com o objetivo de revisitar algumas práticas e dogmas trazidos pela dominação moderna ao design. Com isso, objetiva-se pinçar alguns pontos da história do Design brasileiro e estabelecer algumas de suas relações com os estudos decoloniais e com o carnaval brasileiro.

Palavras chave Design, Decolonialidade, Carnaval. 


\section{Decoloniality: Perspectives and Contributions to Design in Brazil}

Abstract The article makes a brief historical note of decolonial thought and its legacy to revisit some practices and dogmas brought by modern domination to design. We are going to address some points in the history of Brazilian Design and establish some relations with decolonial studies and the Brazilian carnival.

Keywords Design, Decoloniality, Carnival.

\section{Descolonialidad y carnaval: algunas perspectivas y aportes al diseño en Brasil}

Resumen El artículo hace una breve nota histórica del pensamiento decolonial y su legado para revisar algunas prácticas y dogmas traídos por la dominación moderna al diseño. Con esto, el objetivo es señalar algunos puntos en la historia del Diseño brasileño y establecer algunas de sus relaciones con los estudios decoloniales y con el carnaval brasileño.

Palabras clave Diseño, Descolonialidad, Carnaval. 


\section{Introdução}

A discussão sobre decolonialidade pode ser considerada não só urgente, mas de fundamental importância para a o mundo globalizado, sobretudo, no que concerne ao seu desenvolvimento nos países denominados periféricos (Cardoso, 2018) ou, para seguir a conceituação de Boaventura de Sousa Santos (2018), nos países do Sul. Quando observamos, em retrospecto, o processo de colonização das Américas, este foi um empreendimento que se justificou pela rotulação dos povos originários do Sul global como inferiores. Além disso, esse regime contribuiu para criar uma divisão artificial entre o que seriam as metrópoles, consideradas centros da civilidade para os quais justificava-se todo o tipo de exploração da outra parte do mundo que, diante dessa dinâmica, tornava-se subalterna. A violência econômica e epistemológica praticada e naturalizada por séculos deixou consequências que são facilmente percebidas nas nossas estruturas econômicas e sociais que, até o presente, continuam amplamente colonizadas. No âmbito profissional, e para adentrarmos especificamente em nosso objeto, não foi diferente: o legado colonial também serviu como base para o Ensino do Design e reverbera na atuação de profissionais da área em diversos setores. Portanto, os estudos decoloniais podem contribuir com os desafios desse setor, principalmente para trilhar um caminho possível para se desvencilhar de práticas hegemônicas que pouco, ou nada, refletem a rica diversidade existente na América Latina. Revisitar a nossa história e a história do Design é necessário, já que se concordarmos com Rafael Cardoso, "ao redescobrirmos o passado, não resta dúvida que estamos também a reinventar o presente." (CARDOSO, 2010, p.7). A dimensão utópica dessa proposição nos guiará em nossas reflexões e, decerto, é imprescindível para que possamos pôr em discussão a força impositiva daquilo que Sousa Santos (2018) denomina de dominação moderna que, por meio do capitalismo, do colonialismo e do patriarcado, logrou articular um modo de vida ancorado na dinâmica de exclusões abissais, incontornáveis, mas que para manter a globalização funcionando, não pode reconhecer-se como tais.

\section{Estudos Decoloniais: Uma breve explanação de suas ideias e de seus conceitos}

Para entender os estudos decoloniais e como surgem, é importante conhecermos seis pontos principais nos quais estão ancorados o seu arcabouço teórico. O primeiro deles postula a vinculação incontornável da modernidade às navegações e ao consequente domínio do Atlântico pela Europa, não à Revolução Industrial ou ao Iluminismo; o segundo, a simultânea estruturação do capitalismo através da acumulação e exploração global; o 
terceiro, o entendimento da modernidade como fenômeno universal composto por relações desiguais de poder; o quarto, que essas relações desiguais de poder entre a Europa e seus outros caracterizam a subalternização das práticas e subjetividades dos povos dominados; o quinto, que a subalternização da maioria da população mundial se estabelece a partir de dois eixos estruturais baseados no controle do trabalho e no controle da intersubjetividade, e, por fim, o sexto, denuncia a designação do eurocentrismo/ ocidentalismo como a única forma específica de produção de conhecimento e subjetividades na modernidade. (ELIZALDE, FIGUEIRA e QUINTERO, 2019)

O termo decolonialidade ganha relevo no final dos anos 1990, na América Latina, por meio da articulação de teorias de pensadores identificados ao grupo modernidade/colonialidade (ESCOBAR, 2003), cuja herança espiritual mescla referências diversas, que vão da teoria crítica europeia à teoria feminista chicana, dos estudos subalternos à teologia da libertação, dos estudos pós-coloniais à filosofia africana, entre outras. O MC identifica-se a um coletivo formado por intelectuais situados em diversas universidades, com a proposta de realizar um movimento epistemológico necessário à renovação crítica e utópica das ciências sociais na América Latina no século XXI.

A narrativa através de uma perspectiva contra-hegemônica é uma característica trazida pelos estudos decoloniais, que se contrapõe à forma como a História do Brasil é ensinada tradicionalmente. Por exemplo, os livros didáticos são apenas uma parte da herança deixada pelo legado do colonialismo, que apresenta aos alunos e alunas como nossa História foi construída, narrada por uma perspectiva eurocêntrica, ocidental, a partir do norte global e pelos olhos do colonizador. Tudo isso ilustrado com imagens e textos que contribuíram para a sedimentação de um imaginário discriminatório presente até hoje em nossa sociedade pelo racismo estrutural. É importante também mencionar um outro movimento relacionado a esses estudos, conhecido como feminismo decolonial, e que tem contribuído com riquíssimas críticas ao pensamento hegemônico ao trazer mais possibilidades e aberturas através das estruturas de raça, classe e gênero e que, em uma de suas críticas, denuncia a inexatidão do que aprendemos nos bancos escolares: que o Brasil foi descoberto em 1500 por Pedro Álvares Cabral. Essa afirmação pode ser considerada um símbolo muito pontual da colonização do nosso pensamento. Isso quer dizer que as pessoas inseridas no sul global se descrevem a partir do olhar do colonizador e essa é a marca da nossa heteronomia, um conceito que se opõe ao de autonomia. O que hoje se chama "Brasil" foi construído em cima do apagamento de memórias de povos originários que aqui habitavam, representantes de etnias e nações diversas, distribuídas de acordo com a territorializações próprias, que nada têm a ver com as fronteiras atuais do país. Apesar de detentores de distintos hábitos e línguas, todos foram reduzidos a um só epíteto genérico: índios. Essa nomenclatura é devida ao fato de que os navegadores europeus supostamente chegaram à América por acaso, ao desviarem-se do caminho para as Índias, que oficialmente seria seu destino (CASTRO, 2020). 


\section{Considerações acerca dos termos colonialismo e colonialidade}

No arcabouço dos estudos decoloniais, alguns conceitos foram forjados, e muitas vezes pouco compreendidos, como colonialismo e colonialidade, termos parecidos, porém com significados diferentes entre si. No livro Decolonialidade e Pensamento Afrodiaspórico, organizado por Ramón Grosfoguel e Nelson Maldonado Torres (que integraram o grupo MC) e Joaze Bernardino Costa, em sua introdução, descrevem a diferença entre esses termos, portanto, quando se pensa em colonialismo, este é uma referência ao processo de dominação político-militar que se desenvolveu para garantir a exploração do trabalho e das riquezas de um determinado território e de seu povo, sempre em benefício de terceiros. Já a colonialidade é muito mais complexa e profunda, e continua a vigorar quando o processo de colonialismo é superado pelos processos de independência de nações antes vinculadas politicamente às metrópoles, mas que ainda se manifesta de forma estrutural através do pensamento, das hierarquias globais e da cultura colonizada.

Quijano (2020,) é incisivo ao afirmar que o eurocentrismo não é uma perspectiva cognitiva exclusiva dos europeus, mas que afeta, também, todos aqueles povos que foram educados a partir dessa perspectiva. Portanto, a base de nosso pensamento e de nossa prática em diversas áreas de atuação dá-se pelas vias estruturais da colonização, que teve como objetivos a exploração, a dominação, a expropriação e o consequente extermínio de diversos povos, cujas terras e bens contribuíram para o estabelecimento de determinados padrões de vida e de produção no Norte global. Consequência disso, também, é aquilo que Sousa Santos (2018) denomina de linha abissal, que permitiu, nos países do Sul global, a naturalização da morte, da violência, do feminícidio e da tortura em proporções que não atingem mesmo as camadas mais desprivilegiadas no Norte.

Enquanto o colonialismo denota uma relação política e econômica de dominação colonial de um povo ou nação sobre outro, a colonialidade refere-se a um padrão de poder que não se limita às relações formais de dominação colonial, mas que envolve, também, as formas pelas quais as relações intersubjetivas se articulam a partir de posições de domínio e subalternidade de viés racial (HOLLANDA, 2020). Ou seja, o colonialismo está mais associado ao período de invasão e controle político que pode ser feito de outro espaço geográfico, e a colonialidade relaciona-se com a fase em que a colônia se torna ex-colônia, pois já tem sua própria estrutura política, mas ainda sofre as consequências da época em que foi praticada a colonização através da exploração de suas terras, riquezas naturais e de seus povos originários. Assim como o colonialismo, a colonialidade traz consigo os mecanismos perversos das situações prévias e que mantém a expropriação de terras e de recursos, desta vez, porém, não somente por meio de apropriação estrangeira, como também por via dos mecanismos do mercado e da globalização financeira. Isso acarreta uma situação em que, nas 
ex-colônias, mesmo após os processos de independência política, grande parcela dos sujeitos nativos continua despossuída. Não somente terras e recursos são deles retirados, mas esses processos são justificados por formas de pensamentos relacionados à colonização e à autocolonização. Os corpos também não são isentos da exploração feita pelo trabalho de maneira que os mantém em um status inferior ao da maioria do proletariado metropolitano (TORRES, 2019).

A colonialidade deslegitima o que não está dentro dos padrões eurocêntricos e ocidentais de civilização. Despreza e julga como inferior o que considera ser o "outro", inclusive o outro lado do mundo, como sendo invisível, composto pelos conhecimentos populares, leigos, plebeus, camponeses, indígenas. $\mathrm{O}$ colonialismo como fenômeno histórico precede e origina a colonialidade enquanto matriz de poder, mas a colonialidade sobrevive ao colonialismo.

\section{Colonialidade do Poder, do Ser e do Saber}

No texto Uma Breve História dos Estudos Decoloniais, (ELIZALDE, FIGUEIRA e QUINTERO, 2019), os autores abordam o conceito de colonialidade do poder, de Aníbal Quijano (1918-2018), que se desdobra, em outros autores, em nomenclaturas como colonialidade do ser, do saber, de gênero e da natureza. A principal consequência dessa forma de controle é o surgimento de um sistema inédito de dominação e de exploração social, e um novo modelo de conflito. Nesse cenário histórico geral, a colonialidade do poder configura-se a partir da organização de um desmedido sistema de dominação cultural que controlará a produção e a reprodução de subjetividades sob o amparo do eurocentrismo e da racionalidade moderna, que hierarquiza a população mundial.

Por sua vez, a noção de colonialidade do ser, proposta pelo acadêmico Nelson Maldonado-Torres, entende a modernidade como uma conquista permanente na qual o constructo "raça" vem justificar a promulgação da não ética da guerra, que permite o avassalamento total da humanidade do outro. $\mathrm{O}$ autor aponta a relação entre a colonialidade do saber e do ser, sustentando que é a partir da centralidade do conhecimento na modernidade que se pode produzir uma desqualificação epistêmica do outro (ELIZALDE, FIGUEIRA e QUINTERO, 2019).

A colonialidade do saber, por seu turno, poder ser entendida como todo o sequestro de conhecimento que aconteceu durante o período de colonização, assim como o seu apagamento. Sousa Santos (2010) elabora o conceito de epistemicídio para retratar o fenômeno consequente da colonização dos saberes de povos originários e do Sul global, que, por meio do racionalismo moderno, passa a considerar como reconhecível e verdadeiro apenas o que era produzido epistemologicamente pelos países do Norte global. 


\section{Design e Decolonialidade: Entre a modernidade e o multiculturalismo}

Quando nos voltamos para as práticas profissionais e de ensino do design em nosso país, claramente esbarramos com os limites delineados nas esferas mais amplas que determinaram a formação da sociedade brasileira. Isto porque:

\footnotetext{
Os resultados das ações dizem muito sobre o homem e sua cultura. Talvez o conjunto de artefatos digam mais sobre a sociedade de uma determinada época, do que os livros de história. Eles contam sobre experiências que nada mais são do que conhecimentos passados de geração a geração mutáveis e, ao mesmo tempo, permanentes em suas origens. Produção, utilização, disseminação, enfim, todo o processo que abarca a relação do homem com seus artefatos ou coisas, falando genericamente, se traduzem na cultura material da sociedade em que se insere. (Maynardes, Magalhães Viana, Moreno de Siqueira e Gomes Queiroz, 2020, p. 4).
}

Observar as realizações e os desenvolvimentos das Artes Aplicadas em solo nacional contribui para identificarmos práticas entranhadas em nossos costumes locais, sejam elas participantes da História oficial, sejam elas resquícios de habilidades que foram debeladas ao longo de nosso processo de colonização. Alguns grupos de estudos de design como o Design e Opressão, têm buscado relacionar os estudos decoloniais com a referida área. Para estabelecermos um diálogo entre o design e os estudos decoloniais, é importante mencionar que a trajetória do design no Brasil também foi afetada pela modernidade/colonialidade, ou seja, como em todas as outras áreas, a colonização também estruturou as práticas desse setor no Brasil. Pater (2020) enfatiza a impossibilidade de separar o design da vida pessoal ou da política. $O$ autor ressalta, também, que a tradição moderna da Europa ocidental não pode mais ser apontada como uma linguagem visual neutra, ainda que isso não constitua exatamente ativismo, visto que esse reconhecimento é apenas um dos passos necessários rumo a uma prática mais responsável e uma sociedade mais ética, no sentido da transformação das estruturas arraigadas da colonização. Afinal, em todos os setores da sociedade esse período de modernização, industrialização e ascensão de uma sociedade de consumo parece ter atingido seu colapso através de um modelo econômico que tem encontrado dificuldades para se sustentar.

Uma das consequências da modernidade/colonialidade para o design brasileiro foi a ênfase na racionalidade como via única de percepção, e que se passa por uma maneira de consciência local sobre a realidade do nosso país. Isto parece ter se fixado em consequência de uma ideologia ala- 
vancada na primeira modernidade, quando se pensava poder inovar em escala planetária por meio do domínio da ciência e da técnica para "conduzir a massa humana, de maneira uniforme, por uma única estrada, uma sociedade programada e projetada para o bem de todos" (MORAES, p.166, 2005).

A década de 1960, no Brasil, foi marcada pela abertura da primeira Escola de Design (ESDI), e por um paradigma de fabricação industrial de massa, que se voltava para a produção de artefatos padronizados. Atualmente, porém, observamos uma tendência de reverter esse caminho, com a indústria buscando nichos para atender à demanda por diferenciação (CARDOSO, 2010). Talvez, essa rebeldia em relação à padronização tenha suas raízes em fins dos anos 1960 e início dos 1970, quando a contracultura traz relevo aos debates sobre o meio ambiente e a questão política de países então identificados ao Terceiro Mundo, o que contribuiu para a "formação de uma nova consciência em nível mundial do papel do design e da tecnologia" (CARDOSO, 2010, p. 219,). Na história do design, a narrativa não foge da estrutura colonial, e para tentar romper com essa prática hegemônica, um ponto de partida importante pode ser refletir sobre uma prática do design mais aproximada de uma população local, uma região específica, periférica e que, muito provavelmente, não será representada pelos padrões europeus e ocidentais em suas necessidades. Conforme Cardoso (2008) ressalta, Victor Papanek, nos anos 1970, já tinha proposto uma concepção de design voltada aos problemas básicos, que combatia o consumismo desenfreado e a espoliação ecológica. Em sua proposta, aspecto central era que os designers voltassem sua atenção para a solução de problemas sociais.

A cultura pós-moderna, de acordo com Moraes (2005), coloca em questão várias características fortemente ligadas ao modelo e à cultura moderna, como a rigidez de linguagem, a linearidade, o cientificismo e a austeridade formal. O pós-modernismo surge através de um destaque cada vez maior de sociedades multiculturais e multiétnicas, plurais. No design, essa transição cultural também começa a ser percebida e valorizada nos projetos e produtos desenvolvidos por designers conectados e comprometidos com a representatividade da diversidade cultural brasileira, cada vez mais expressa e percebida após os anos 1990, seja na produção de artefatos ou em outras atividades da área. $O$ designer pode trazer sua contribuição através de sua bagagem histórica que serve como repertório para a expressão dessa criatividade, mais local, periférica, regional e representativa. Como exemplo no Brasil, temos o carnaval com as escolas e seus samba-enredo, que tem sido um importante veículo de conscientização histórica e política, por sua atuação contra-hegemônica. 


\section{Mestiçagem e Design Brasileiro: E o que isso tem a ver com o carnaval?}

As aberturas da pós-modernidade para a quebra de hegemonia do paradigma moderno eurocêntrico trazem consigo a oportunidade de reconhecermos a diversidade e o multiculturalismo que formam o tecido da sociedade brasileira. Isto traz, também, novos caminhos a serem explorados pelo design, em busca de realizações condizentes com os padrões estéticos locais (MORAES, 2005). Ainda assim, não se pode deixar de perceber as influências da modernidade/colonialidade na supervalorização do aspecto racional que se mantém presente no atual design brasileiro.

Avançando para a categoria de produtos-serviços (que são desvinculados dos processos fabris convencionais), há a demanda cada vez maior e mais veloz de uma difusão do bem-estar social para os povos distantes do centro. A decolonialidade no design pode ser relacionada com essa prática do design mais recente, situado na América Latina e no final dos anos noventa.

No entanto, em solo nacional, temos uma prática já consolidada há muitas décadas que acena para o design na perspectiva decolonial: as atividades que envolvem a criação dos espetáculos em torno do carnaval. Essa festa, tão relevante no Brasil, traz a possibilidade de despontar como um possível exemplo de aplicação dos conceitos da cultura múltipla e mestiça na arte e no design local. Um aspecto muito específico da nossa cultura e que surge com o carnaval brasileiro é a profissão de "designer carnavalesco", um profissional com a responsabilidade de pensar a caracterização de carros alegóricos e fantasias das escolas de samba. o designer carnavalesco tem o desafio de conseguir comunicar, por meio da imagem dos carros alegóricos e das fantasias dos participantes, o enredo e o tema da escola que representa (MORAES, 2005). O carnaval também tem a capacidade de tecer críticas à política e às estruturas coloniais através de suas letras, frequentemente abordando uma narrativa contra-hegemônica por algumas escolas que dão prioridade às histórias contadas pelos povos originários, às pessoas de origem afro-latino-americana e às mulheres negras periféricas que, por tanto tempo, foram consideradas pessoas subalternas ou inferiores. As histórias que antes foram silenciadas para promover seu apagamento e a produção de conhecimento que, muitas vezes, foi apropriada pelo colonizador tem nos estudos decoloniais a oportunidade de ser trazida aos holofotes desse grande espetáculo apreciado internacionalmente por meio dos enredos das escolas de samba. A possibilidade de reverberação desse evento é gigantesca e, apesar de esse ser um momento de festa e de diversão, o mesmo pode ser utilizado para dar voz aos esquecidos e para se ter uma perspectiva mais educativa e politizadora. 
O termo carnavalização traz o significado e sentido de polifonia, de uma força centrífuga da linguagem, da relatividade alegre das coisas, o perspectivismo e o desempenho, a participação na desordem louca da vida, a imanência do riso. Pode ser o carnaval na verdade, considerado o antissistema, pelos seus elementos lúdicos, subversivos. (MORAES, 2005, p.184).

O carnaval da tradicional escola de samba Mangueira, fundada na década de 1920, trouxe como samba-enredo em 2019 uma homenagem à Marielle Franco (27 de jul. 1979), vereadora, defensora dos Direitos Humanos e das minorias, covardemente assassinada no dia 14 de março de 2018 no Rio de Janeiro. A execução de Marielle é considerada, por muitos movimentos ativistas e, principalmente, por grupos feministas como um feminicídio político por sua postura socialmente combativa e, principalmente, por ser uma mulher negra, da periferia, lésbica e que nunca se deixava calar diante das opressões sofridas. Com o título "História para ninar gente grande", a composição da Mangueira criticou profundamente os desdobramentos políticos, sociais e históricos a partir do século XV, desde o julgamento moral dos povos, a invenção do conceito de raça, o colonialismo e a colonialidade.

Numa palavra: destruiu, peça a peça, a poderosa ficção chamada Evolução, que tem nos informado de que há povos primitivos e povos avançados; de que há o antiquado e o moderno; de que há a razão e o corpo; de que há a ciência e a arte; de que há homens inteligentes e mulheres sensíveis. Polos distanciados pelo valor, que gera preconceito, discriminação e dominação. (PEREIRA, 2019)

Um dos trechos da letra do samba-enredo, em tom de denúncia, levou seus integrantes a cantarem junto com o público: "A história que a história não conta/ O avesso do mesmo lugar/ Na luta é que a gente se encontra." Um ótimo exemplo de como pensar o papel social do carnaval através de um eixo decolonial, que pode ser percebido, também, nas imagens utilizadas para ilustrar a alegoria, as fantasias, e o conteúdo que expõe e reforça o lugar da luta para que a memória de Marielle esteja sempre presente. Leandro Vieira (25 de jul. de 1983), carnavalesco reconhecido por sua atuação e por sua militância através do carnaval, levou à Mangueira seu pensamento sobre o contexto político e social do país, e a escola angariou reconhecimento tornando-se a vencedora do carnaval de 2019. 


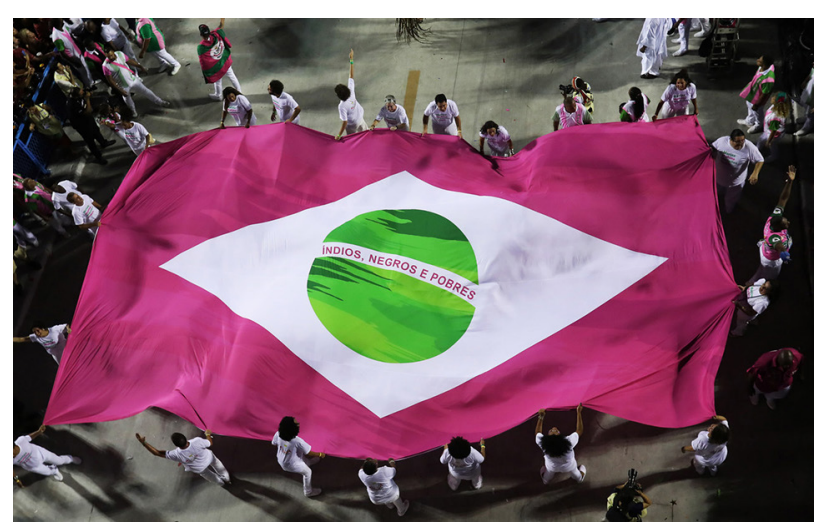

Fig 1. "Bandeira Brasileira"

Fonte: https://www.premiopipa.com/leandro-vieira/ 2019

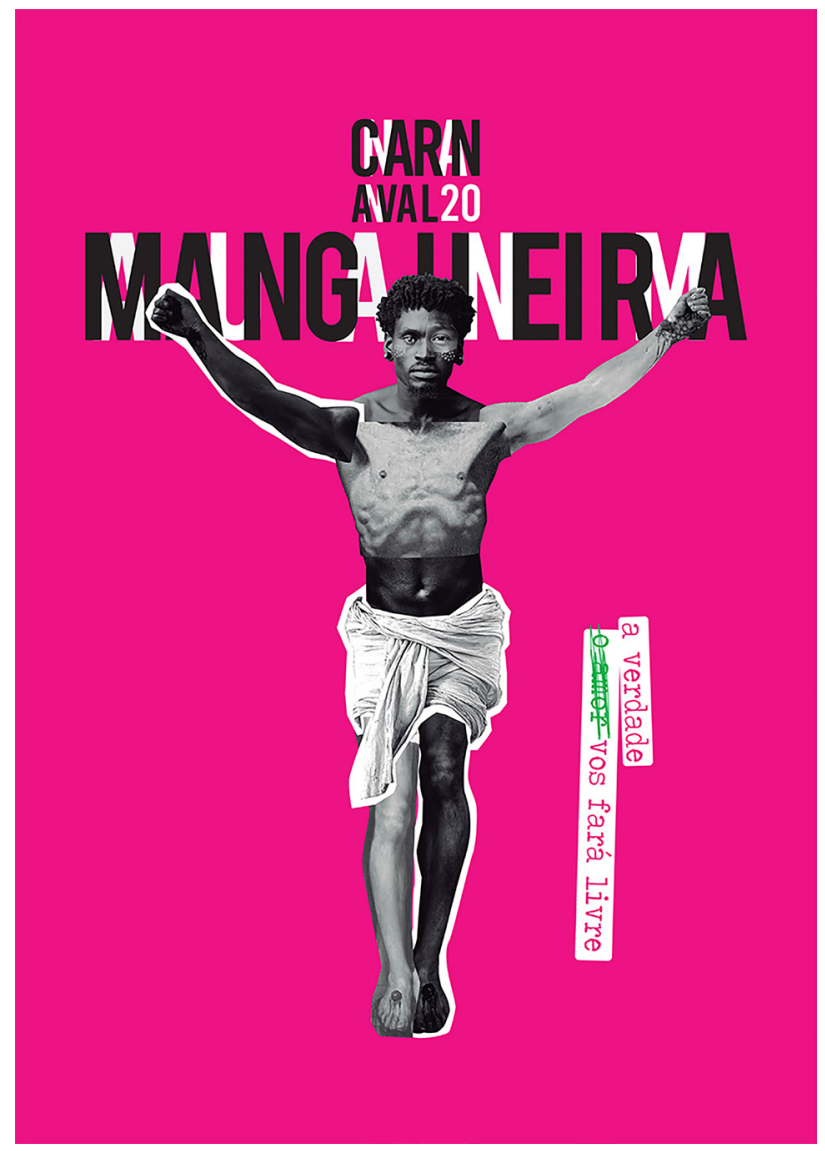

Fig 2. "Jesus é índio, negro, mulher também"

Fonte: http://www.mangueira.com.br/logo/ 2020
O estandarte (fig.1) confeccionado nas cores que representam a escola de samba, os tradicionais verde e rosa, remetem à nossa bandeira nacional, venerada por grupos de extrema--direita que reforçam preconceitos, violência e racismo. Esses grupos radicais e negacionistas são a corporificação do imaginário, amplamente colonizado em seus modos de pensar e de ser no mundo. Precisamos ressaltar que essa bandeira, um símbolo cooptado pela ultradireita, é redesenhada e ressignificada pela Mangueira não apenas com outras cores, mas também com novos dizeres: "índios, negros e pobres" surge em lugar de "ordem e progresso", o lema positivista comtiano que, por sua vez, já havia falseado a proposição original, "O Amor por princípio e a Ordem por base; o Progresso por fim". É propositalmente e simbólico dar destaque a essas palavras que representam a verdadeira origem da nossa história e que precisa ter visibilidade e representatividade, povos que contribuíram para a construção do Brasil, ricos em suas culturas, em suas formas de existir e em sua produção de conhecimento. Suas expressões, por muitos séculos, foram caladas e consideradas como inferiores ao padrão hegemônico europeu ocidental.

No ano de 2020, a Mangueira novamente surpreende com o samba-enredo "A verdade vos fará livre", que contou a história de Jesus e imaginou o que ocorreria se sua volta ocorresse atualmente, em um contexto de tanta intolerância e perseguição. $O$ samba reforça a história de luta de Cristo contra o Estado opressor e, novamente, Leandro Vieira, designer carnavalesco da escola traz isso muito bem traduzido através das fantasias, dos carros alegóricos e do material de comunicação visual da Mangueira.

Nessas peças, há uma crítica inequívoca ao país onde muitas pessoas se consideram cristãs, mas ainda contribuem com discursos de ódio e violência, cada vez mais conservadoras e intolerantes com a diversidade sexual, cultural e étnica. Na figura abaixo, uma outra bandeira com o destaque para os dizeres "Estado Assassino", uma crítica ao estado necropolítico ${ }^{1}$ que, quando não mata, deixa morrer especificamente as pessoas que não se enquadrem num perfil padronizado, seja ele de corpos, de comportamentos, da expressão de pensamentos ou de qualquer manifestação que seja considerada uma afronta ao cidadão de bem e cristão. 
Fig 3. "Fantasias" | Fonte: www.hypeness.com.br/2019/07/mangueira-tera-como-tema-em-2020-a-volta-de-jesus-em-um-mundo-intolerante

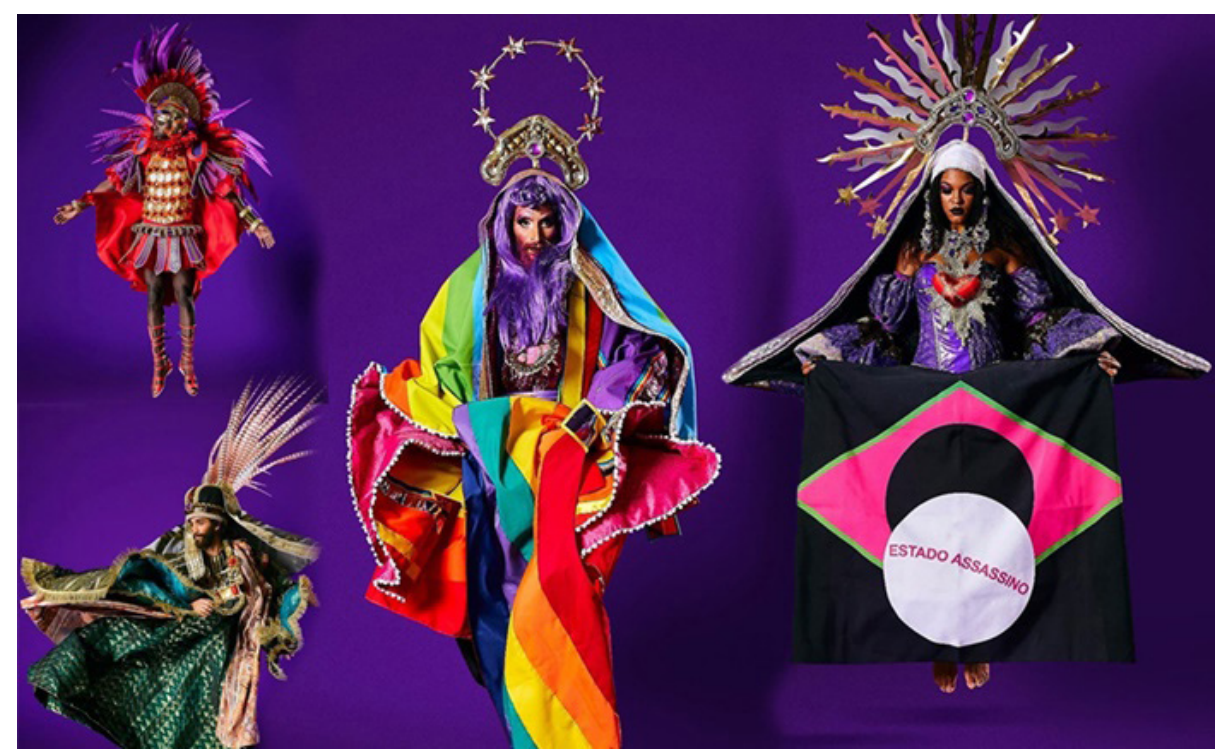

Portanto, atualmente, o design se tornou também uma atividade que deixa de estar somente no âmbito projetual, mas passa ao patamar intelectual (MORAES, 2005). Ou seja, quando se pensa em trazer os estudos decoloniais para o design e para pensar em suas contribuições, trilhamos um caminho para que seja possível associar o multiculturalismo brasileiro, como um novo e possível caminho para o desenvolvimento do design local e periférico. Pela perspectiva da cultura, é importante relacionar o pensamento decolonial com uma prática do design cada vez mais próxima da decolonialidade, engajada na luta antirracista. Um exemplo dessa prática é encontrado nos desfiles de 2019 e de 2020 da Mangueira, que foram baseados em política e em história, com a intenção de expor outro olhar sobre os fatos que aconteceram e que até hoje são negligenciados. Com o auxílio de fantasias, da comunicação visual, da arquitetura e da decoração dos carros alegóricos, assim como do samba-enredo, a escola soube traduzir o que é a colonialidade, representada por toda violência até hoje sofrida pela população brasileira, herdeira de anos de colonialismo.

Quando olhamos para os valores culturais presentes no design brasileiro, reconhecemos suas diferentes faces e observamos a diversidade de suas características. Ao assumirmos que não existe unicidade no âmbito do design local no Brasil, estaremos dando um passo na direção em que nenhuma das culturas existentes no país foi subestimada em relação às outras. Moraes (2005) ressalta que pensamento acerca do design pode ser aproximado ao pensamento decolonial quando deixamos explícito que, ao trabalharmos com uma perspectiva projetual homogênea, isso significa, implicitamente, que algumas culturas foram subestimadas para dar espaço àquela que se sobressaiu como modelo único. Esta é, portanto, a reprodução do padrão eurocêntrico ocidental como única possibilidade de existência, que oprime tudo o que é diferente disso, considerando-o sem valor, inferior, menos importante. 
A nova realidade do design brasileiro precisa nos aproximar de uma estética multicultural, em que se percebe a presença de signos híbridos e de uma energia singularmente brasileira. É relevante salientar que este novo modelo local, que está em formação, tem a possibilidade de capturar com mais precisão o pluralismo ético, étnico e estético do Brasil.

Os estudos decoloniais têm essa potência de revelar ao povo latino-americano a busca por sua verdadeira história, que hoje já pode ser amplamente difundida e contada, inclusive em um evento reconhecido como uma das festas mais populares do mundo. O carnaval, considerado um momento de alegria e que, por muitas décadas, foi um alento às classes populares, voltando-se à fantasia em oposição às dificuldades cotidianas, à opulência em contraste com as necessidades diárias e à celebração de tradições do povo reprimidas pelas elites em outras esferas foi se modificando e se tornando um importante estímulo ao turismo e à divulgação da cultura brasileira em nível global. É significativo que esse evento, cujo alcance foi ampliado pela presença de celebridades e de turistas que compram suas fantasias para participar dos desfiles ao lado das comunidades de cada escola de samba não perca totalmente seu vínculo com as populações que historicamente contribuíram para a sua importância atual.

o design aplicado ao carnaval pode inspirar todo o campo em nosso país, ao mostrar que é possível conjugar diversão e sensibilidade estética a uma perspectiva engajada, que pluraliza a visão que temos de nosso povo e de seu papel no mundo. $O$ design pode contribuir com uma nova construção de imaginário antirracista e descolonizado, cujo caminho pode ser amparado pelo pensamento e pelos estudos decoloniais.

1 Necropolítica: Conceito criado por 0 filósofo camaronês Achille Mbembe (27 jul. 1957), autor de 'Necropolítica' e 'Crítica da razão negra', pode ser considerada uma política de morte, sustentada na dimensão da racialização, que extrapola, na medida em que a condição subalterna reservada aos negros, amplia e aponta para o devir-negro do mundo. 


\section{Referências}

CARDOSO, Rafael. Design para um mundo complexo. São Paulo: Editora UBU, 2017.

CARDOSO, Rafael. Uma introdução à história do design. São Paulo: Editora Blucher, 2008. BERNARDINO-COSTA, Joaze; MALDONADO-TORRES, Nelson; GROSFOGUEL, RAMÓN. Decolonialidade e Pensamento Afrodiaspórico. Belo Horizonte: Editora Autêntica, 2019.

ELIZALDE, Paz Concha; FIGUEIRA, Patricia; QUINTERO, Pablo. Uma breve história dos estudos decoloniais. São Paulo: Museu de Arte de São Paulo Assis Chateaubriand, 2019

ESCOBAR, Arturo. "Mundos y conocimientos de otro modo. El programa de investigación de modernidad/colonialidad latinoamericano." Tabula Rasa, vol. , no. 1, 2003, pp.51-86. Redalyc, https://www.redalyc.org/articulo.oa?id=39600104 HOLLANDA, Heloisa Buarque. Pensamento feminista hoje perspectivas decoloniais. Rio de Janeiro: Bazar do Tempo, 2020.

MAYNARDES, A. C. ., Magalhães Viana, D., Moreno de Siqueira, N. ., \& Gomes Queiroz, S. . (2020). Design, Culture and Materiality. DAT Journal, 5(3), 167-181. https://doi.org/10.29147/ dat.v5i3.265

MIGNOLO, Walter D. A colonialidade está longe de ter sido superada, logo, a decolonialidade deve prosseguir. São Paulo: Museu de Arte de São Paulo Assis Chateaubriand, 2019

MORAES, Dijon de. Análise do Design Brasileiro - entre a mimese e a mestiçagem. São Paulo: Editora Blucher, 2006.

MORAES, Dijon de. Fenomenologia do design contemporâneo. DAT Journal, v. 5, n. 2, p. 7-24, 12 jun. 2020. https://doi.org/10.29147/dat.v5i2.188

PATER, Rubens. Políticas do Design. São Paulo: Editora UBU, 2020.

PEREIRA, Nilton Mullet. Jornal da Universidade: Um acontecimento chamado Mangueira. Universidade Federal do Rio Grande do Sul: 2019 RODRIGUES, Carla; AIRES, Suely. Dossiê | A leitura de Achille Mbembe no Brasil. 2018. Disponível em: https://revistacult.uol.com.br/home/dossie-leitura-de-achille-mbembe-no-brasil/. Acesso em: 18 de jan. de 2020.

SANTOS, Boaventura de Sousa; Maria Paula Menezes et al. (org.). Construindo as Epistemologias do Sul - Antologia Essencial. Buenos Aires: CLACSO, 2018.

SANTOS, Boaventura de Sousa; MENEZES, Maria Paula. Epistemologias do Sul - São Paulo: Cortez, 2010. 